\title{
Photovoice as a Tool for Critical Reflection in Communities of Practice for Teachers' Professional Identity Development
}

\author{
Hing Kwan TO \\ Department of Psychology, The Education University of Hong Kong, \\ Hong Kong \\ tohingkwan@hotmail.com
}

\begin{abstract}
Professional identity is very important in teaching practice. There is a consensus in the literature that critical reflection can help novice teachers to develop a professional identity. Written form reflective tools such as diaries, reflective papers, and logbooks are conventional instruments for critical reflection among novice teachers. However, written reflective tools have several shortcomings: a) they overly rely on verbal communication; b) there are no standardized guidelines for critical reflection using written-form reflective tools, and c) using written-form reflective tools is an intrapersonal activity. Photovoice has emerged as a new tool for critical reflection in the last few decades. Using photovoice, novice teachers critically reflect through photographs rather than writing. Empirical research has standardized the critical reflective procedure of photovoice. Communities of practice are a signature feature of photovoice. Establishing a community of practice is an effective way for novice teachers to develop a professional identity via interpersonal interaction within a group, sharing their photographs and reflections. Empirical research shows that photovoice enables novice teachers to develop a professional identity. This paper describes the disadvantages of writtenform reflective tools and outlines an innovative method of encouraging novice teachers to perform critical reflection.
\end{abstract}

\section{Keywords}

critical reflection - photovoice - community of practice - novice teacher 
Teaching is an interactive communication practice that elicits learning (Hirst, 1971). However, this communication practice is used not for persuasion, but rather to help students to construct the knowledge, values, and attitudes required for their development. Social learning theory tells us that students construct knowledge based on a teacher's verbal information and non-verbal communication, such as body gestures and intonation (Bandura, 1969). Research has shown that professional identity is strongly and positively correlated with verbal and non-verbal communication (Cohen, 2009; Quinlisk, 2009). Teachers can gain professional knowledge, such as classroom management, pedagogical, or subject knowledge, during teacher training, but they often do not receive training in verbal or non-verbal communication skills. There is no systematic training to enable student teachers to shape their professional identity.

Reflection is a way to construct a professional identity (Korthagen \& Vasalos, 2005). Many scholars have recommended that teaching professionals engage in reflective practices. For example, Dewey (1938) argued that teachers can gain skills and knowledge through their teaching experiences (learning by doing). Further, Schon (1987) explained that teaching professionals can generate new knowledge by reflecting on their teaching practice. According to Jay and Johnson (2002), reflection can be classified into three categories: descriptive reflection, comparative reflection, and critical reflection. Descriptive reflection aims to describe a phenomenon. At this level of reflection, the teacher can delineate the situation. Comparative reflection allows teachers to adopt an alternative perspective to reframe their experience. Through comparative reflection, teachers can appreciate others' perspectives on the situation and evaluate their own experience. Critical reflection is the highest level of reflection in teaching practice. When teachers perform critical reflection, they can construct a new perspective, new knowledge, or new solutions from their experiences. Therefore, reflective practice facilitates teachers' professional development and furthermore, critical reflection is the most effective way to enhance teacher professional identity (Shandomo, 2010).

Research has shown that teachers can develop a professional identity through critical reflection (Trede et al., 2012). Over the last few decades, scholars have put forward many theories to define professional identity (Beijaard et al., 2004). Some have suggested that professional identity is a teacher's selfconcept (Knowles, 1992) or role (Goodson \& Cole, 1994). Others have claimed that professional identity is a set of shared attributes within the same domain of people (Judyth, 2001). Others maintain that professional identity is 
constructed by evaluating experience and the interaction between the professional and the environment (Beijaard et al., 2004). Critical reflection is an effective method of evaluating the interaction between the professional and the environment and involves problem identification, self-inquiry, and selfreflection (Schon, 1987, Larrivee, 2000).

Teacher professional identity begins to be developed in teacher training. Novice teachers need to obtain more teaching experience and seek advice from experienced colleagues or mentors for professional teacher identity consolidation. Critical reflection occurs through teaching experiences or based on advice from experienced colleagues or mentors and if critical reflection is performed by just one teacher, it is less valuable than that involving multiple teachers (Cinnamond and Zimpher, 1990). As a result, critical reflection is an intrapersonal cognitive activity (Mezirow, 1998). Some scholars have argued that critical reflection is an interpersonal activity (Brookfield, 2009). Interactions with the professional community can lead to effective critical reflection (Brookfield, 2009; Cinnamond \& Zimpher, 1990). At the same time, a professional community has shared attributes that regulates the behavior of group members (Judyth, 2001, Hogg \& Reid, 2006). Hogg and Reid (2006) further elaborated that norms furnish the same pattern of attributes and behaviors as interpersonal interaction. As a result, critical reflection and professional identity should involve interpersonal interaction.

\section{The Limitations of Critical Reflection Tools}

Verbal communication is an effective way to share personal reflections with the wider professional community (Cinnamond \& Zimpher, 1990). Many instruments for critical reflection are available, such as diaries, portfolios, reflective journals, and narratives based on photographs, but these have several limitations.

First, writing a diary or reflective journal increases a teacher's workload (Attard \& Armour, 2006). Novice teachers need to adjust to a new teaching environment and meet the requirements of their country's educational system (Gavish \& Friedman, 2010). Novice teachers experience frustration in their teaching practice (Brill \& McCartney, 2008). Moreover, their heavy workload may cause burnout (Karsenti \& Collin, 2013). Teachers feel exhausted after finishing all of their tasks at school. Novice teacher lack the time and energy to write about their critical reflections (Attard \& Armour, 2006).

Second, there is no standardized instruction in critical reflection. Many scholars have focused on critical reflective learning (Dewey, 1938; Mezirow, 
1998; Schon, 1987). Therefore, many theories delineate the relationship between critical reflection and knowledge construction. Dewey believed that critical reflection is oriented towards problem-solving (Mezirow, 1991). It involves hypotheses and testing (Yost, Senter, \& Forlenza-Bailey, 2000). Dewey claimed that novice teachers should gain experiences (of problems) before they can make critical reflections (Askeland \& Fook, 2009). Smith (2011) stated that critical reflection involves "reflection-on-action". Scholars have stated that novice teachers need to perform critical reflection but have not outlined procedures for critical reflection. Fook (2015) noted that critical reflection should be highly flexible to strengthen the function of critical reflection in knowledgebuilding. Pultorak (1996) claimed that guidelines should be provided to encourage novice teachers to reflect on their teaching practice. Research has shown that novice teachers find it difficult to perform critical reflection without instruction (Fisher, 2003; Attard \& Armour, 2006; Reid, 2009). Guidelines supported by empirical evidence are thus needed for teacher training, but there is no standardized approach to training teachers in the use of writtenform reflective tools.

Third, most reflective tools do not address the importance of interpersonal interaction. Scholars have claimed that critical reflection is self-reflection (Mezirow, 1991). Critical reflection allows a less experienced teacher to construct new knowledge and obtain new insights (Rigg \& Trehan, 2008). Social constructivism argues that interpersonal interaction enhances the effectiveness of knowledge building (Green \& Gredler, 2002). However, critical reflection and professional identity are most effectively constructed through interpersonal interaction (Cinnamond \& Zimpher, 1990; Hogg and Reid, 2006). Furthermore, digital platforms such as Facebook and blogs allow teachers to share critical reflections and receive feedback simultaneously (Yang, 2009; Rubrico \& Hashim, 2014) in multimedia or written forms. Is indirect communication an effective form of interaction? Horwitz (2012) found that undergraduate student engagement in a reflection course increased when it involved face-toface interactions with classmates. The level of engagement is highly correlated with professional identity formation within a group (Wenger, 2010). In short, effective critical reflection should be time-efficient and assisted by clear and standardized instructions; it should also take written and multimedia forms, and involve direct face-to-face communication.

Photovoice is an instrument that can fulfill all of these criteria. Photovoice was developed to allow people with poor verbal literacy skills to perform reflection 
(Wang, 1997). Wang (1997) examined a rural area of China. She was aware that many Chinese women are verbally illiterate. Therefore, she asked the participants to take photographs to represent their ideas, and provided guidelines for the participants to elaborate on their photographs. The photographs and instructions enabled the participants to share their ideas and communicate much more in-depth information about their needs. According to Wang and Pies (2004), photovoice has three components in teacher training. First, teachers take photographs representing aspects of their teaching lives and ask questions about them. Then, during group discussion, they identify a shared issue or concern, and each shares a photograph that relates to the common theme. The teachers then work together to find a solution to each concern. Novice teachers are free to share and elaborate on their photographs, and give feedback (Langdon et al., 2014).

Photovoice provides teachers with a platform for direct face-to-face communication, and to connect with the public. Teachers are asked to take daily photographs of their teaching lives. Usually, a photovoice group meets weekly (Graziano, 2011; Horwitz, 2012; Langdon et al., 2014). Before a photovoice session, teachers select photographs that best represent their concerns. During the group session, teachers share their photographs and ideas by following the PHOTO protocol which asks respondents to:

(1) delineate the photograph;

(2) identify the event in the photograph;

(3) explain why they took a picture of it;

(4) explain how the photograph relates to their life; and

(5) explain how it could lead to improvements for teachers (Horwitz, 2012; Langdon et al., 2014).

After a teacher has shared his/her photograph, other members can give feedback. The teachers then write a summary of all of the photo frames. After the photovoice group sessions conclude, the photographs and photo frames are exhibited to the public. The five PHOTO protocol steps encourage novice teachers to progressively reflect deeper (Melanie et al., 2017). Studies have shown that participants who follow these five questions are better able to consolidate their insights and ideas (Wang \& Burris, 1997).

Photovoice provides novice teachers with clear and standardized process and guidelines on critical reflection. During the photograph selection, teachers reflect on experiences and identify the most significant (Horwitz, 2012). This process requires the teachers to analyze both their experience and their reflection. The sharing session allows teachers to find the roots of their issues, solutions to problems, and future strategies to avoid these problems $(\mathrm{Ru}-$ brico \& Hashim, 2014). With feedback from other group members, teachers absorb other teachers' knowledge and ideas to construct new insights, new 
perspectives, or new solutions to issues (Yang, 2009). After teachers have absorbed suggestions from group members, they take action by following up on the ideas that have emerged from the group (Langdon et al., 2014).

Critical reflection through photovoice can empower novice teachers (Bow et al., 2010). Photovoice emphasizes the use of photographs to assess needs and promote dialogue in small or community groups (Wang \& Burris, 1997). Through group discussion, novice teachers can share their needs and suggest solutions with other group members. This conversation improves novice teachers' competence and sense of control and empowers them. Through this process of discussion and critical reflection their professional identity is further developed. (Bowers, 2017; Horwitz, 2012; Strack et al., 2004). Teachers enjoy photovoice because they can express their needs to the community (Rubrico \& Hashim, 2014).

The photovoice strategy recognizes the importance of interpersonal interaction. A multiplicity of perspectives is one of the main components of this approach to critical reflection. Novice teachers can widen their perspective through interpersonal communication, group discussions, sharing their photographs and reacting to group feedback (Cinnamond \& Zimpher, 1990; Wang \& Burris, 1997). Participants receive support from others through face-to-face communication and may receive new insights or ideas through the discussions, thereby developing their professional identity (Horwitz, 2012; Langdon et al., 2012; Wenger, 2010).

Photovoice also offers teachers a platform to express their needs to the community. After the discussion session, the teachers write a summary of their photo frames which are exhibited to the public. People in the community are encouraged to attend the exhibition and can see which photographs the participants selected for the group discussion and read the description of each photograph. In this way, found that photovoice provides a channel for audiences to appreciate and understand the needs or reflections of participants. Novice teachers find that the exhibition provides a platform to transfer their ideas to, and thus influence, the community as they develop their professional identity (Cinnamond \& Zimpher, 1990; Horwitz, 2012; Rubrico \& Hashim, 2014).

Photovoice, Community of Practice, and Professional Identity Development

Wenger (1996) proposed a concept of community of practice to facilitate professional identity development among novice teachers. The community of practice is an informal learning group (Wenger, 1996). The members of the 
learning group share the same goals, beliefs, and roles (Li et al., 2009). The community members freely share their feelings, experiences, and knowledge within the group. Achieving a common objective is the main reason for community formation. A community of practice emphasizes member initiative: individuals form a group and share their experiences voluntarily (Printy, 2008). Research has shown that a community of practice provides an effective platform for building professional identity (Davis, 2006; Wenger, 1998; Yang, 2009).

A community of practice depends on verbal communication. According to social constructivism, verbal communication is a crucial tool for constructing knowledge or identity (Green \& Gredler, 2002). During the group conversation, group members receive verbal information and professional support (Wenger et al., 2002). Photovoice provides a useful platform for novice teachers to establish a community of practice that develops their individual professional identity as they share their teaching experiences and pursue a common goal. Graziano (2011) explored pre-service teachers' feedback on the photovoice approach. Most felt interested in sharing their stories. They felt that they received emotional support during the photovoice session. Graziano's research indicated that photovoice is an instrument to facilitate preservice teachers' reflection in a group atmosphere. The community of practice emphasizes the interpersonal relationship within the group (Wenger, 2010).

\section{5}

\section{Implementing Photovoice Reflection with Community of Practice}

Reflective professional practice has been strongly recommended and an important part of teacher education part in recent time (Sim, 2006). Wenger (1999) identified that community of practice should have three elements, engagement, imagination, and alignment.

First, engagement involves active involvement in the group conversation (Sim, 2006). The school should provide a mentoring scheme to support novice teacher to accommodate the new environment. In a traditional mentoring approach, an experienced teacher (mentor) is assigned a novice teacher (mentee) based on the subject teaching. It is preferable that mentors and mentees who share the same educational philosophy and similar teaching values can be matched otherwise it may be difficult to develop active engagement (Blair, 2008). If not available at their own school, it might be possible for the school to invite experienced teachers form elsewhere nearby who will share their experience, strategy, and skills to be a mentor (Cuddapah \& Clayton, 2011). According to Wenger (1999), group members share a similar value that can strengthen the engagement. However, to develop their professional identity and to become 
an effective teacher the novice does not necessarily require a mentor, although it may be useful (Gless \& Moir, 2001).

Second is imagination, which refers to creating a picture that connects with the reality (Sim, 2006). Photovoice can be useful tool in connecting with the reality. When a novice teacher takes the photo of what he/she wants to share, the perspective, structure and colour of the photo are designed by that novice teacher. After taking the photo, the novice teacher should reflect on this photo, making the connection with the photo and the reality (Graziano, 2011).

The last element of a community of practice is alignment which is defined as making the reflection transferrable (Sim, 2006). During the photovoice session, novice teachers should actively share their photos and reflections, which enables transferability (Schell \& Ferguson, 2009; Wenger, 1999). Novice teachers complained that there was extremely heavy workload interrupting them to join the sharing session, so the school should provide enough time for mentor and mentees sharing since an effective community of practice can enhance teacher's sustainability and professional identity (Cuddapah \& Clayton, 2011; Mak \& Pun, 2015). Therefore, it is suggested that the school provide sufficient time allocation for sharing and creating an opportunity for conversation between mentor and novice teachers.

\section{$6 \quad$ Conclusion}

Critical reflection is important for novice teachers to develop as they become effective teachers and develop their professional identity. Novice teachers find it hard to use common written critical reflective formats due to their heavy workloads (Attard \& Armour, 2006). Photovoice is an innovative critical reflective tool in visual form that provides standard guidelines to assist teachers to develop a professional identity (Lee, 2005). Moreover, research suggests when novice teachers become part of a community of practice that uses photovoice and holds conversations that share teaching experiences, the interactions enabled are effective in developing common goals and professional identity (Printy, 2008). However, since there has been no empirical research on the wider effects of professional identity development using photovoice and community of practice for teachers, further research is needed.

\section{References}

Anderson, J. (1986). Health skills: the power to choose. Health Education Journal, 45(1), $19-24$. 
Attard And, K., \& Armour, K. (2006). Reflecting on reflection: A case study of one teacher's early-career professional learning. Physical Education and Sport Pedagogy, $11(3), 209-229$.

Blair, D. V. (2008). Mentoring novice teachers: Developing a community of practice. Research Studies in Music Education, 3o(2), 99-117.

Bandura, A. (1969). Social-learning theory of identificatory processes. In D. A. Goslin (Ed.), Handbook of Socialization Theory and Research, 213-262. Rand McNally \& Company.

Beijaard, D., Meijer, P. C., \& Verloop, N. (2004). Reconsidering research on teachers' professional identity. Teaching and Teacher Education, 20(2), 107-128.

Bowers, H. P. (2017). A case study of photovoice as a critical reflection strategy in a field seminar. Practice Digest, 7(2), 1-10.

Brill, S., \& McCartney, A. (2008). Stopping the revolving door: Increasing teacher retention. Politics \& Policy, $36(5), 75^{0}-774$.

Brookfield, S. (2009). The concept of critical reflection: promises and contradictions. European Journal of Social Work, 12(3), 293-304.

Cinnamond, J. H., \& Zimpher, N. L. (1990). Reflectivity as a function of community. In R. T. Clift, W. R. Houston, and M. C. Pugach (Eds.), Encouraging Reflective Practice in Education. An Analysis of Issues and Programs (pp. 57-72). Teachers College Press.

Cohen, J. L. (2008). 'That's not treating you as a professional': Teachers constructing complex professional identities through talk. Teachers and Teaching: Theory and Practice, 14(2), 79-93.

Collin, K., \& Karsenti, T. (2013). The role of online interaction as support for reflective practice in preservice teachers. Formation et Profession, 20(2), 64-81.

Cuddapah, J. L., \& Clayton, C. D. (2011). Using Wenger's communities of practice to explore a new teacher cohort. Journal of Teacher Education, 62(1), 62-75.

Davis, J., \& Wilson, S. M. (200o). Principals' efforts to empower teachers: Effects on teacher motivation and job satisfaction and stress. The Clearing House, 73(6), 349-353.

Day, C., Elliot, B., \& Kington, A. (2005). Reform, standards and teacher identity: challenge of sustaining commitment. Teaching and Teacher Education, 21, 563-577.

Dewey, J. (1938). Experiential education. Collier.

Dinkelman, T. (2000). An inquiry into the development of critical reflection in secondary student teachers. Teaching and Teacher Education, 16(2), 195-222.

Fisher, K. (2003). Demystifying critical reflection: Defining criteria for assessment. Higher Education Research \& Development, 22(3), 313-325.

Fook, J. (2015). Reflective practice and critical reflection. In Lishman J (Ed.), Handbook for Practice Learning in Social Work and Social Care (pp. 440-454). Jessica Kingsley Publishers.

Gavish, B., \& Friedman, I. A. (2010). Novice teachers' experience of teaching: A dynamic aspect of burnout. Social Psychology of Education, 13(2), 141-167. 
Gless, J., \& Moir, E. (2001). When veteran meets novice. Journal of Staff Development, $22(1), 64-65$.

Goodson, I. F., \& Cole, A. L. (1994). Exploring the teacher's professional knowledge: Constructing identity and community. Teacher Education Quarterly, 21(1), 85-105.

Graziano, K. J. (2011). Working with English language learners: Preservice teachers and photovoice. International Journal of Multicultural Education, 13(1).

Green, S. K., \& Gredler, M. E. (2002). A review and analysis of constructivism for schoolbased practice. School Psychology Review, 31(1), 53-70.

Hirst, P. H. (1971). What is teaching? Journal of Curriculum Studies, 3(1), 5-18.

Hogg, M. A., \& Reid, S. A. (2006). Social identity, self-categorization, and the communication of group norms. Communication Theory, 16(1), 7-30.

Horwitz, J. (2012). Photovoice as a critical reflection methodology. In R. Flessner (Ed.), Agency Through Teacher Education: Reflection, Community, and Learning (15-24). Rowman \& Littlefield.

Jay, J. K., \& Johnson, K. L. (2002). Capturing complexity: A typology of reflective practice for teacher education. Teaching and Teacher Education, 18(1), 73-85.

Kirkman, B. L., Rosen, B., Tesluk, P. E., \& Gibson, C. B. (2004). The impact of team empowerment on virtual team performance: The moderating role of face-to-face interaction. Academy of Management Journal, 47(2), 175-192.

Knowles, G. J. (1992). Models for understanding pre-service and beginning teachers' biographies: Illustrations from case studies. In I. F. Goodson (Ed.), Studying Teachers' Lives (99-152). Routledge.

Korthagen, F., \& Vasalos, A. (2005). Levels in reflection: Core reflection as a means to enhance professional growth. Teachers and Teaching, n1(1), 47-71.

Larrivee, B. (2000). Transforming teaching practice: Becoming the critically reflective teacher. Reflective Practice, 1 (3), 293-307.

Leroux, M., \& Théorêt, M. (2014). Intriguing empirical relations between teachers' resilience and reflection on practice. Reflective Practice, 15(3), 289-303.

Li, L. C., Grimshaw, J. M., Nielsen, C., Judd, M., Coyte, P. C., \& Graham, I. D. (2009). Evolution of Wenger's concept of community of practice. Implementation Science, $4(1), 11-18$.

Mak, B., \& Pun, S. H. (2015). Cultivating a teacher community of practice for sustainable professional development: Beyond planned efforts. Teachers and Teaching, $21(1), 4-21$.

Mezirow, J. (1991). How critical reflection triggers transformative learning. In J. Mezirow (Ed.), Fostering Critical Reflection in Adulthood (pp. 1-20). Jossey-Bass.

Mezirow, J. (1998). On critical reflection. Adult Education Quarterly, 48(3), 185-198.

Printy, S. M. (2008). Leadership for teacher learning: A community of practice perspective. Educational Administration Quarterly, 44(2), 187-226. 
Pultorak, E. G. (1996). Following the development process of reflection in novice teachers: Three years of investigation. Journal of Teacher Education, 47 (4), 283-291.

Quinlisk, C. C. (2009). Nonverbal communication, gesture, and second language classrooms: A review. In McCafferty, S. \& Stam, G. (Eds.), Gesture: Second Language Acquisition and Classroom Research (pp. 37-56). Routledge.

Reid, E. S. (2009). Teaching writing teachers writing: difficulty, exploration, and critical reflection. College Composition and Communication, 6r(2), 197-221.

Rigg, C., \& Trehan, K. (2008). Critical reflection in the workplace: is it just too difficult? Journal of European Industrial Training, 32(5), 374-384.

Robinson, M. (2003). The mentor-mentee match: Preserving tradition or driving the profession? In C. Conway (Ed.), Great beginnings for music teachers: Mentoring and supporting new teachers (133-137). MENC-The National Association for Music Education.

Rubrico, J. G. U., \& Hashim, F. (2014). Facebook-photovoice interface: Empowering non-native pre-service English-language teachers. Language Learning \& Technology, $18(3), 16-34$.

Sachs, J. (2001). Teacher professional identity: Competing discourses, competing outcomes. Journal of Education Policy, 16(2), 149-161.

Schon, D. A., (1987). Educating the reflective practitioner. Jossey-Bass.

Shandomo, H. M. (2010). The role of critical reflection in teacher education. SchoolUniversity Partnerships, 4(1), 101-113.

Strack, R. W., Magill, C., \& McDonagh, K. (2004). Engaging youth through photovoice. Health Promotion Practice, 5(1), 49-58.

Sim, C. (2006). Preparing for professional experiences - incorporating pre-service teachers as 'communities of practice'. Teaching and teacher education, 22(1), 77-83.

Smith, L. M, Andrusyszyn, M. A., \& Laschinger, H. K. S. (2010). Effects of workplace incivility and empowerment on newly-graduated nurses' organizational commitment. Journal of Nursing Management, 18, 1004-1015.

Trede, F., Macklin, R., \& Bridges, D. (2012). Professional identity development: a review of the higher education literature. Studies in Higher Education, 37(3), 365-384.

Wang, C., \& Burris, M. A. (1997). Photovoice: Concept, methodology, and use for participatory needs assessment. Health Education \& Behavior, 24(3), 369-387.

Wang, C. C., \& Pies, C. A. (2004). Family, maternal, and child health through photovoice. Maternal and Child Health Journal, 8(2), 95-102.

Wenger, E. (1996). How we learn. Communities of practice. The social fabric of a learning organization. Healthcare Forum Journal, 39, 20-26.

Wenger, E. (1999). Communities of practice: Learning, meaning, and identity. Cambridge University Press. 
Wenger, E. (2010). Communities of practice and social learning systems: The career of a concept. In C. Blackmore (Ed.), Social Learning Systems and Communities of Practice (pp. 179-198). Springer.

Wenger, E., McDermott, R., \& Snyder, W. M. (2002). Cultivating communities of practice: A guide to managing knowledge. Harvard Business School Press.

Yang, S. H. (2009). Using blogs to enhance critical reflection and community of practice. Educational Technology \& Society, 12(2), 11-21.

Yost, D. S., Sentner, S. M., \& Forlenza-Bailey, A. (2000). An examination of the construct of critical reflection: Implications for teacher education programming in the 21st century. Journal of Teacher Education, 51(1), 39-49. 